\title{
1 Metal release under anaerobic conditions of urban soils of four European
}

\section{cities}

${ }^{1}$ Università di Torino, DiSAFA - Chimica agraria, Largo Paolo Braccini 2, 10095 Grugliasco (Torino), Italy

${ }^{2}$ Instituto de Recursos Naturales y Agrobiología de Sevilla (CSIC), Apartado 1052, 41080, Sevilla, Spain

${ }^{3}$ Kmetijski inštitut Slovenije, Hacquetova ulica, 17, SI-1000 Ljubljana, Slovenia

${ }^{4}$ WestCHEM, Department of Pure and Applied Chemistry, University of Strathclyde, 295

Cathedral Street, Glasgow G1 1XL, UK

Corresponding author:

Elio Padoan

DiSAFA- Chimica agraria

Largo Paolo Braccini 2, 10095 GRUGLIASCO (Torino) - Italy

Ph: +390116708517

Email: elio.padoan@unito.it

\section{Abstract}

Urban soils contamination may represent an environmental threat in view of their proximity to humans. The ecological homogenization of urban areas has been postulated and, as the sources of pollution are the same in most European cities, it is possible that soil contamination is another factor of convergence. The current climate change with consequent increase of extreme rain events may affect the mobility of potentially toxic elements (PTE) thus increasing the risks. If the soil is submerged, Eh decreases and causes the solubilization of Fe and Mn oxides, which are important carriers of PTE. We compared the release of $\mathrm{Cu}, \mathrm{Pb}$ and $\mathrm{Zn}$ from 48 soils of four cities (namely Glasgow, Ljubljana, Sevilla and Torino) when submerged for up to 30 days. A decrease of the redox potential was observed in all soils after a few days and an increase of $\mathrm{Mn}$ and then $\mathrm{Fe}$ in solution. $\mathrm{Cu}, \mathrm{Pb}$ and $\mathrm{Zn}$ were consequently released to the solution according to the general soil contamination. Despite the marked differences in soil properties, the reaction to anaerobiosis appeared to be similar in all samples indicating that waterlogging of urban soil contaminated with PTE may pose a serious environmental risk and substantiating the hypothesis of ecological convergence. 
Keywords: urban soils; climate change; potentially toxic elements; redox; flooding

\section{Introduction}

Urban soils are a well-known sink for the pollutants that are produced by a variety of human activities. A review of available data (Ajmone-Marsan and Biasioli 2010) has shown that most world cities are contaminated by potentially toxic elements (PTEs). Burning of fossil fuels, industrial production and waste disposal are among the main sources of contaminants such as $\mathrm{Cu}$, $\mathrm{Pb}$ and $\mathrm{Zn}$. In fact, these elements have been recognized as being characteristic diffuse contaminants of urban areas (Imperato et al. 2003; Biasioli et al. 2006; Sharma et al. 2015). Indeed, many of the studied cities are more similar in soil contamination than any other characteristic. The hypothesis of a general ecological homogenization caused by urbanization was postulated by McKinney (2006) and was later confirmed for six urban areas in the United States of America (Groffman et al. 2014). Subsequently, Pouyat et al. (2015) compared the soils of five cities and observed a convergence of the properties affected by anthropogenic processes and associated with biogenic processes. In urban areas of Europe, the sources of contamination are similar, so it is possible that soil contamination is another indicator of convergence of urban environments.

The total PTE content is but one parameter that can define the quality of a soil but it carries little information about the actual threat that the presence of the PTEs pose to human health or to other ecosystems. It is now generally accepted that chemical fractionation or solution data (NRC 2003) give a better insight into the risk connected to PTE contamination, and several studies (Madrid et al., 2008; Poggio et al. 2009; Sialleli et al. 2011) have confirmed the importance of the available and bioaccessible fractions of PTE in the assessment of their hazardousness to humans in the urban context.

The transfer of the contaminants to an adjacent environmental compartment - water, air or biota is not solely dependent on the chemical reactivity of the element; the soil matrix can abruptly change its properties and reduce its equilibrium concentration for contaminants, thus releasing some bound components. This is the case with rapid changes of the redox potential that occur, for example, when a soil is submerged. Although trace metals are rarely directly involved in the redox reactions, during submersion iron and manganese oxides are solubilized, thus releasing the PTEs that are adsorbed onto their surfaces or occluded within their mineral structure (Davranche and Bollinger 2000; Cornell and Schwertmann 2003; Du Laing et al. 2009; Violante et al. 2010; Vodyanitskii and Plekhanova 2014). This would increase the potential toxicological effects that come from PTE contamination of the soil (Alderman et al. 2012). Schulz-Zunkel et al. (2013) described PTE contamination of the sediments of the river Elbe in Germany and indicated that changes in redox potential were one of the main factors that may switch sediment from sink to 
metals from mine-spoil contaminated soils in response to submersion and ensuing anaerobiosis. Shaheen et al. (2014) established that the periodic inundation of contaminated floodplain soils affected the temporal dynamics of $\mathrm{Cd}, \mathrm{Co}, \mathrm{Cu}, \mathrm{Ni}$, and $\mathrm{Zn}$ due to changes in $\mathrm{Eh}-\mathrm{pH}$, dissolved organic carbon, and in the chemistry of $\mathrm{Fe}, \mathrm{Mn}$ and $\mathrm{S}$. An increase of metal mobility in flooded urban soils was observed by Florido et al. (2011) and was attributed to the dissolution of Fe and Mn oxides. Notable examples of the consequence that soil submersion can have on PTE release comes from the work of Su et al. (2008) and of Fox et al. (2009) who studied the mobilization of contaminants after the flooding caused by hurricane Katrina in New Orleans (USA). Apart from that exceptional and extensive episode, local conditions that are conducive to the onset of anaerobiosis are frequent in urban soils, due mainly to the alteration of soil hydrology because of soil sealing and compaction (Du et al. 2015). In recent years, however, an increase in the number and intensity of extreme rain events has been observed (IPCC 2013; Gallant et al. 2014). Buzatu (2016) reported that Europe has seen a $60 \%$ increase in extreme weather events over the past three decades. Global climate change not only causes warming, but also alters the precipitation patterns, so that ecosystems will have to deal with an increased frequency of extreme precipitation events (IPCC 2013; NASEM 2016).

In the Piemonte region, in NW Italy, a study of the data between 1930 and 2004 has revealed an increase in the intensity of extreme rain events (Ciampittiello et al. 2013). Similarly, Jones et al. (2014) observed an increase of the probability of extreme rain events in south Scotland in the period 1961-2010. As thunderstorms are generally more frequent over urban areas, due to the formation of a heat island (Scalenghe and Ajmone-Marsan 2009), the risk of local soil flooding is enhanced (Jha et al. 2011).

The scope of this work was to evaluate the effects that changing redox conditions caused by flooding can have on the potential release of $\mathrm{Cu}, \mathrm{Pb}$ and $\mathrm{Zn}$ from contaminated soils from four European cities. A more general aim was to verify if the postulated ecological homogenization of urban environment would also apply to these biotic reactions of soils.

\section{Materials and methods}

Twelve soils were selected from each of the cities of Glasgow (UK), Ljubljana (SL), Sevilla (ES) and Torino (IT) (Table 1) among those that had been previously described by Madrid et al. (2006) and Biasioli et al. (2007). The selection was made to obtain a variety of soil properties and of concentrations of $\mathrm{Cu}, \mathrm{Pb}$ and $\mathrm{Zn}$ in order to represent the wide diversity of these urban soils. In addition to potential flooding from exceptional rain events, all four cities are built on riverbanks so there is also a possibility that their soils could be inundated. Indeed, the city of Torino was flooded in 1994 and 2000 when heavy rains occurred over the steepest areas of its catchment. 
Table 1 Description of the cities

\begin{tabular}{cccccc}
\hline \multirow{2}{*}{ City } & Location & $\begin{array}{c}\text { Size of } \\
\text { urban area } \\
\left(\mathrm{km}^{2}\right)\end{array}$ & Population & $\begin{array}{c}\text { Mean annual } \\
\text { rainfall } \\
(\mathrm{mm})\end{array}$ & $\begin{array}{c}\text { Mean annual } \\
\text { temperature } \\
\left({ }^{\circ} \mathrm{C}\right)\end{array}$ \\
\hline \hline Ljubljana & $46^{\circ} \mathrm{N} / 14^{\circ} \mathrm{E}$ & 95 & 260000 & 1352 & 10.8 \\
Sevilla & $37^{\circ} \mathrm{N} / 6^{\circ} \mathrm{W}$ & 135 & 706000 & 540 & 18.2 \\
Torino & $45^{\circ} \mathrm{N} / 8^{\circ} \mathrm{E}$ & 130 & 865000 & 750 & 12.6 \\
Glasgow & $55^{\circ} \mathrm{N} / 4^{\circ} \mathrm{W}$ & 176 & 600000 & 1100 & 8.9 \\
\hline
\end{tabular}

111

112 Surface soil horizons were sampled using stainless steel shovels from 0 to $10 \mathrm{~cm}$. Samples were 113 air-dried, gently crushed and sieved to $<2 \mathrm{~mm}$ with plastic sieves to reduce metal contamination 114 (ISO 11464). A portion of the sample was further ground to $<0.15 \mathrm{~mm}$ for aqua regia $\left(\mathrm{HCl} / \mathrm{HNO}_{3}\right.$, $1153: 1$ solution) digestion (ISO 11466). The aqua regia extracts were analysed for $\mathrm{Cu}, \mathrm{Fe}, \mathrm{Mn}, \mathrm{Pb}$, 116 and $\mathrm{Zn}$ by ICP-OES. Triplicates were made for all samples and results accepted when the 117 coefficient of variation was under 5\%. A blank and soil CRM BCR 141 R reference material (Joint 118 Research Centre - Institute for Reference Materials and Measurements, Geel, Belgium) were 119 included in each batch of analyses for quality control. Results were considered satisfactory when 120 within a range of $\pm 10 \%$ from the certified value. Particle size distribution was determined by 121 sedimentation and sieving; the $\mathrm{pH}$ was measured in $\mathrm{CaCl}_{2}$ solution at a 1:5 soil:solution ratio and 122 organic carbon and sulphur by elemental analyzer. The content of sulfur was always lower than the 123 detection limit.

124 Anaerobic microcosms were set up by placing $45 \mathrm{~g}$ of soil in $250 \mathrm{ml}$ dark glass bottles and $150 \mathrm{ml}$ 125 of a $0.01 \mathrm{M} \mathrm{CaCl}_{2}$ solution (Supplementary Material, Fig. 1S). The flasks were flushed with $\mathrm{CO}_{2-}$ 126 free $\mathrm{N}_{2}$ and tightly sealed. Ten $\mathrm{ml}$ of the suspension were sampled at 6 hours, and 1, 5, 9, 14, 21, 127 and 30 days, filtered with $0.45 \mu$ m nylon filters and the metals in solution $(\mathrm{Cu}, \mathrm{Fe}, \mathrm{Mn}, \mathrm{Pb}$ and $\mathrm{Zn})$ were measured having had care to maintain anoxia. The $\mathrm{pH}$ and $\mathrm{Eh}$ of the solutions were measured under $\mathrm{N}_{2}$ in a parallel set of samples. Measurements of $\mathrm{pH}$ were done by a polymer combination electrode, and the Eh was estimated by a redox platinum electrode (Crison Micro CM, 2201, Crison

131 Instruments S.A. Spain). At the end of the experiment, the soil samples were air-dried at $40^{\circ} \mathrm{C}$ and 132 gently crushed in an agate mortar. Sequential extraction was carried out before and after the experiments according to the revised BCR protocol (Rauret et al. 1999). The procedure is summarised below: 
- Step 1 (water/acid soluble and exchangeable fraction): $40 \mathrm{ml}$ of $0.11 \mathrm{~mol} \mathrm{l}^{-1}$ acetic acid was added to $1 \mathrm{~g}$ soil and shaken for $16 \mathrm{~h}$ at room temperature. The extract was separated from the solid by centrifugation, decanted and stored at $4{ }^{\circ} \mathrm{C}$. The residue was washed with distilled water and the washings discarded.

- Step 2 (reducible fraction): $40 \mathrm{ml}$ of $0.5 \mathrm{~mol} \mathrm{l}^{-1}$ hydroxylammonium chloride (adjusted to $\mathrm{pH} 1.5)$ was added to the residue from step 1 , and the extraction performed as described for step 1.

- Step 3 (oxidisable fraction): the residue from step 2 was digested with hydrogen peroxide then $50 \mathrm{ml}$ of $1.0 \mathrm{~mol} \mathrm{l}^{-1}$ ammonium acetate (adjusted to $\mathrm{pH}$ 2) was added and the extraction performed as described for step 1.

- Step 4 (residual fraction): the residue from step 3 was extracted with aqua regia using the same procedure as described above for the whole soil.

All determinations were carried out in triplicate. The sum of fractions was compared with the results of aqua regia digestion of the whole soils to determine metal recovery with the BCR procedure and recoveries were within $90 \%$ and $110 \%$ for all samples.

Data interpretation and statistical analysis (Pearson correlations and analysis of variance) were carried out using Microsoft Excel 2013 and IBM SPSS 25. To better define associations between analytes, we used Principal Component Analysis (PCA). We carried out the chemometric treatment on the whole data set of 48 samples and we used, alternatively, the chemico-physical characteristics, the whole data on metals release and specific release times. All data sets were normalized using Z-scores.

\section{Results and Discussion}

The four cities have soils with different $\mathrm{pH}$ : while Glasgow (GLA) has acidic soils, in Torino (TOR) it ranges from acidity to above neutrality, with a mean value of 6.6, and in Ljubljana (LJU) and Sevilla (SEV) the $\mathrm{pH}$ is slightly above neutrality (Table 2 and Supplementary Material, Table $1 \mathrm{~S})$.

The soils of the latter two cities have an average carbonate content of $19 \%$ and $21 \%$, respectively. The content of organic $\mathrm{C}$ is very variable within and between cities, being highest in Glasgow and lowest in Sevilla. In general, the $\mathrm{C}$ concentrations parallel the climatic conditions of the cities with a North-South organic matter decline. In contrast, the particle-size distribution appears to be remarkably uniform as the majority of the textures are towards a sandy particle-size except for some soils in Sevilla, which show a silty texture. Metal contents reflect the sample selection criteria, showing a wide range of values. In most cases, however, the concentrations are above the respective national legislative thresholds for contaminated soils, as described in Madrid et al. (2006). 
171 In this work we investigated the effect of changing redox conditions on the release of $\mathrm{Cu}, \mathrm{Pb}$ and

$172 \mathrm{Zn}$, typical contaminants of urban soils (Madrid et al. 2006), thus we calculated correlations

173 between the soil properties and metal concentrations using data for all the soils (Supplementary

174 Material, Table 2S). Although the soil properties are widely changing, $\mathrm{Pb}, \mathrm{Zn}$ and $\mathrm{Cu}$ are

175 significantly, though moderately ( $\left.\mathrm{r}_{\mathrm{Cu}-\mathrm{Pb}}=0.70 ; \mathrm{r}_{\mathrm{Cu}-\mathrm{Zn}}=0.65 ; \mathrm{r}_{\mathrm{Cu}-\mathrm{Pb}}=0.50\right)$, correlated, corroborating

176 the observation that, at least in respect of PTE contamination, these urban soils tend to converge.

177

Table 2 Soil properties and metal content (aqua regia)*. $\mathrm{N}$ is 12 for all cities

\begin{tabular}{|c|c|c|c|c|c|c|c|c|c|c|}
\hline \multirow{2}{*}{ Samples } & $\mathrm{pH}$ in & Sand & Silt & Clay & Org. C & $\mathrm{Fe}$ & $\mathrm{Mn}$ & $\mathrm{Cu}$ & $\mathrm{Pb}$ & $\mathrm{Zn}$ \\
\hline & $\mathrm{CaCl}_{2}$ & & $\%$ & & $\%$ & $\%$ & \multicolumn{4}{|c|}{$\mathrm{mg} / \mathrm{kg}$} \\
\hline \multicolumn{11}{|c|}{ Glasgow } \\
\hline Mean & 5.0 & 66 & 26 & 8 & 7.0 & 2.9 & 475 & 89 & 300 & 263 \\
\hline Median & 5.0 & 66 & 27 & 8 & 6.7 & 2.8 & 456 & 82 & 281 & 215 \\
\hline Max & 5.8 & 81 & 35 & 15 & 13.0 & 4.0 & 686 & 194 & 618 & 621 \\
\hline Min & 4.1 & 50 & 16 & 3 & 4.2 & 2.3 & 132 & 41 & 122 & 124 \\
\hline S.D. & 0.6 & 7.3 & 4.9 & 2.9 & 2.3 & 0.5 & 164 & 46 & 141 & 149 \\
\hline CV\% & 11 & 11 & 19 & 38 & 33 & 16 & 35 & 52 & 47 & 57 \\
\hline \multicolumn{11}{|c|}{ Ljubljana } \\
\hline Mean & 7.1 & 46 & 40 & 14 & 5.7 & 2.3 & 866 & 65 & 190 & 223 \\
\hline Median & 7.1 & 48 & 40 & 14 & 5.5 & 2.1 & 854 & 60 & 162 & 193 \\
\hline Max & 7.3 & 57 & 48 & 19 & 8.6 & 3.2 & 1410 & 124 & 388 & 421 \\
\hline Min & 6.9 & 37 & 34 & 8 & 4.2 & 1.3 & 412 & 39 & 115 & 134 \\
\hline S.D. & 0.2 & 5.6 & 4.8 & 2.8 & 1.2 & 0.5 & 319 & 24 & 87 & 79 \\
\hline CV\% & 2 & 12 & 12 & 21 & 21 & 22 & 37 & 38 & 46 & 35 \\
\hline \multicolumn{11}{|c|}{ Sevilla } \\
\hline Mean & 7.2 & 37 & 41 & 22 & 2.5 & 2.1 & 544 & 116 & 364 & 182 \\
\hline Median & 7.2 & 41 & 40 & 23 & 2.8 & 2.0 & 401 & 109 & 326 & 197 \\
\hline Max & 7.4 & 54 & 58 & 33 & 3.7 & 2.7 & 1317 & 229 & 977 & 325 \\
\hline Min & 7.0 & 10 & 27 & 13 & 0.9 & 1.6 & 294 & 25 & 30 & 21 \\
\hline S.D. & 0.1 & 14.3 & 9.8 & 6.7 & 1.0 & 0.3 & 324 & 71 & 311 & 79 \\
\hline CV\% & 1 & 39 & 24 & 30 & 40 & 15 & 60 & 62 & 85 & 44 \\
\hline \multicolumn{11}{|c|}{ Torino } \\
\hline Mean & 6.6 & 68 & 21 & 11 & 3.2 & 3.4 & 736 & 137 & 428 & 264 \\
\hline Median & 6.8 & 64 & 25 & 12 & 3.0 & 3.2 & 686 & 104 & 320 & 243 \\
\hline Max & 7.5 & 88 & 32 & 15 & 5.8 & 5.0 & 1097 & 301 & 1440 & 440 \\
\hline Min & 4.8 & 55 & 7 & 5 & 1.7 & 3.0 & 397 & 35 & 58 & 90 \\
\hline S.D. & 0.8 & 12.2 & 9.2 & 3.3 & 1.3 & 0.5 & 233 & 82 & 431 & 123 \\
\hline CV\% & 12 & 18 & 44 & 31 & 40 & 16 & 32 & 60 & 101 & 47 \\
\hline
\end{tabular}

*Max $=$ maximum; Min $=$ minimum; S.D. $=$ standard deviation; $\mathrm{CV} \%=$ coefficient of variation

181 The maximum acceptable PTE concentrations in soils are regulated in all countries of this study,

182 although with different thresholds or guideline values in the different states. As found in previous 
studies (Madrid et al. 2006), Torino, Glasgow and, to a lesser extent, Sevilla, were the most contaminated cities but the definition of contamination may not be applicable, as the trigger values differ widely between countries.

186 Despite these differences, all legislative limits refer to the total concentrations of PTEs, a metric 187 that does not necessarily refer to the risk posed from the leaching of these elements from soil. Bioavailable and bioaccessible fractions have been studied in last years to offer a more realistic representation of the risk posed to humans and the environment in general (Ajmone-Marsan et al. 2008; Padoan et al. 2017) using extracting agents that mimic the human absorption of the contaminants. While availability and accessibility are estimates based on the nature (solubility, desorbability) of the element and of the soil, the release of PTE due to the chemical reduction and dissolution of the matrix (i.e. Fe, Mn oxides, organic matter) is usually not taken into account. The PTE release depends on various soil properties as the quantity and type of organic matter, Fe and Mn-oxides. Thus, these trigger values would not be suitable in case of flooded soils and a more specific risk-based approach that takes into consideration the parameters governing the metals release is required.

Table 3 Maximum acceptable limits (mg kg-1) in the studied countries or regions applicable to soils of residential or recreational areas (adapted from Madrid et al. 2006).

\begin{tabular}{c|ccc}
\hline Country/ Region & $\mathbf{C u}$ & $\mathbf{P b}$ & $\mathbf{Z n}$ \\
\hline Italy $^{\mathbf{a}}$ & 120 & 100 & 150 \\
Andalucia $^{\mathbf{b}}$ & $150-300$ & $250-350$ & $300-600$ \\
Slovenia $^{\mathbf{c}}$ & $300-500$ & $400-500$ & $500-1000$ \\
UK $^{\mathbf{d}}$ & $60 / 100 / 300$ & $85 / 100 / 530$ & $200 / 300 / 720$ \\
\multicolumn{4}{c}{} \\
a Limit values for residential and garden areas. \\
'Research required" values (ranges instead of single values are given); \\
different values are given for pH below and above 7. \\
c "Limit", "warning" and "critical" values. \\
'CLEA Soil Guideline Values, specific limits with a risk-based approach
\end{tabular}

\subsection{Incubation experiments}

203 Despite the differences between and within cities, the urban soils responded to treatment in a rather uniform way regarding Eh and $\mathrm{pH}$ values. The values of the redox potential (Eh, Figure 1) promptly decreased in all soils regardless of the content of the different redox couples in the soil, e.g. of organic carbon, that would act as an electron donor.

207 The $\mathrm{pH}$ values (Supplementary Material, Fig. 2S) varied accordingly, increasing in most soils. The Sevilla soils showed more erratic values, presumably as a result of the dissolution of the $\mathrm{CO}_{2}$ derived from the carbonates. 
The redox system of the soil is controlled by several variables and the Eh is the result of numerous redox couples acting simultaneously. Together with the $\mathrm{pH}$, it gives a general representation of the reduction or oxidation status, but its value cannot be attributed to any specific reaction, especially in a complex matrix such as the soil. A more reliable indication that the soil has attained an anoxic condition comes from the appearance of some elements in solution. After oxygen and nitrates have been depleted, Mn first and Fe soon after are adopted as the final electron acceptors of the anaerobic metabolism. The solubility of their reduced compounds $-\mathrm{Mn}^{2+}, \mathrm{Fe}^{2+}-$ is greatly increased with respect to the oxidized forms, and so was the concentration of these metals in solution (Figures 2 and 3). In Figure 2 the average Mn concentration in the soil solution is reported for all cities. The concentrations are represented as a percentage of the sum of the fractions exchangeable and reducible of each soil, to improve readability, as soils had very diverse metals concentrations. Exact amounts released from each soil at each time are in the Supplementary Materials, in Tables 3S and 4S. Manganese in solution (Fig. 2) increased from the very beginning of the experiment in almost all soils, although the choice of the sampling aimed at representing the maximum variability in each city, and its concentration appeared to stabilize after a peak at day 5 of submersion. This threshold at day 5 was confirmed using mean release values; values recorded in samplings after $6 \mathrm{~h}$ and 1 day were significantly different for subsequent samples (HSD Tukey test, $\mathrm{p}=0.05$ ) for all cities but Torino. In TOR samples, however, the trend was alike.

229 This indicated that most of the soils attained anoxic conditions in a very similar way, regardless of the properties of the matrix. Electron donors such as low molecular weight organic matter is sufficient to stimulate the action of anaerobic microorganisms that reduce Mn. Iron concentration increased in solution on submersion (Fig. 3) and in general followed the thermodynamic order, appearing in solution after day 5, i.e. after Mn reduction. A threshold day for the concentrations to be significantly different from the beginning was found at day 14 for Torino and Ljubljana soils while at day 21 for Glasgow and Sevilla. The largest amounts of Fe were released from the GLA soils, despite their total Fe concentration being similar to the soils of other cities. It is possible that the low $\mathrm{pH}$ and abundant organic matter in those soils might have enhanced Fe dissolution by complexation (Vodyanitskii and Plekhanova 2014). The lowest values were recorded for the SEV and LJU soils where, in contrast, the high $\mathrm{pH}$ and the presence of carbonates explain the low Fe solubility and the more homogeneous concentration values.

242 The dissolution of $\mathrm{Fe}$ and $\mathrm{Mn}$ oxides brings about an increase in the solution concentration of the 243 PTE that are associated - adsorbed or occluded - to these compounds. Manganese oxides are strong sorbents of PTE and act as natural sinks for contaminants (Borch et al. 2010) and Fe oxides are used to sequester PTE from contaminated soils due to their strong affinity with the oxides (Gasparatos 2013; Liu et al. 2014). 
In the case of copper (Figure 4), a peak in the concentration in solution was observed in all soils although some differences emerged between cities. While the $\mathrm{Cu}$ peak appeared as early as day 5 of submersion in Ljubljana and Sevilla, most of the soils in Glasgow and Torino showed the maximum release around day 10. After the first peak, another increase was observed in Ljubljana and Sevilla soils after the $21^{\text {st }}$ day of the experiment. The decrease in concentration of an element in solution following a maximum is usually attributed to changes in the matrix that are brought about by anoxia: Fe and Mn oxides are only partially dissolved and new surfaces are exposed that can re-adsorb the metals or they can adsorb to, or coprecipitate with, Fe(II)-compounds while organic matter can similarly contribute to the lowering of the concentration in solution (Cornu et al. 2009; Borch et al. 2010; Vink et al. 2010; Frohne et al. 2014). The rise in pH would increase the negative charge on variable-charge minerals, such as Fe-oxides, and augment the probability of surface sorption. The chemistry of $\mathrm{Cu}$ in soil, especially in urban settings, is particularly complex (Biasioli et al. 2010; Borch et al. 2010) as the sources can be very variable: metallurgical and energy-related industry as well as automotive traffic can release $\mathrm{Cu}$ in different forms. This can partly justify the very high levels of readily soluble $\mathrm{Cu}$ in some soils from Glasgow, Sevilla and Torino, the latter showing a concentration as high as $15.3 \mathrm{mg} / \mathrm{kg}$ of $\mathrm{Cu}(7 \%$ of the total $\mathrm{Cu})$ released after the first 6 hours of the experiment. The affinity of this element for organic matter can further obscure the overall picture, as part of the metal can pass into solution as a complex or subsequently to the oxidation of organic complexes rather than the reduction of $\mathrm{Fe}$ and $\mathrm{Mn}$ oxides. While there are sources of point contamination of $\mathrm{Pb}$, this element is a typical diffuse contaminant of urban soils due to its former use as antiknock in gasoline. Similarly to $\mathrm{Cu}, \mathrm{Pb}$ was promptly released to the solution in many soils of Glasgow, Sevilla and Torino (Figure 5) indicating that there are soluble forms of these elements in the soils of all three cities. In Glasgow, most soils showed an increase in concentration towards the end of the experiment, indicating that a substantial $\mathrm{Fe}$ dissolution (Figure 3) is necessary for $\mathrm{Pb}$ to be released. The soils of Torino presented the highest release considering absolute values, but the general trend was similar to that of the other cities. For the soils of Ljubljana, a peak in $\mathrm{Pb}$ concentration was observed after 5 days of submersion, in correspondence with $\mathrm{Mn}$ peaks and another close to the 21 days $\mathrm{Fe}$ peak, reinforcing the hypothesis that $\mathrm{Pb}$ could be closely associated with redox-sensitive oxides. The highest concentrations of $\mathrm{Zn}$ in solution were observed in the soils of Glasgow (Figure 6). In contrast to other elements and to the soils from other cities the concentration of this metal decreased steadily, after an initial peak. It appeared that Zn solubility followed Fe dissolution and $\mathrm{pH}$ increase. In Ljubljana, Sevilla and Torino the release of $\mathrm{Zn}$ appeared to be connected with Fe oxides solubilization. This confirms that this element is associated preferentially to Fe oxides (Van Laer et al. 2010; Vodyanitskii and Plekhanova 2014). These results are in line with those reported by Donner et al. (2012) for Mn and Fe rich soils and by Van Laer et al. (2010) for some Spodosols. 


\subsection{Chemical fractionation}

285 The chemical fractionation of the metals in urban soils offers an insight into the transformations that these undergo after submersion and subsequent oxidation (Table 4).

Table 4 Changes in the proportion of chemical fractions (expressed as $\%$ of the total content)

290

\begin{tabular}{|c|c|c|c|c|c|}
\hline & & GLA & LJU & SEV & TOR \\
\hline \multirow{4}{*}{$\mathrm{Mn}$} & Exchangeable & $35^{*}$ & $52 *$ & $29 *$ & $18^{*}$ \\
\hline & Reducible & $-31 *$ & $-51 *$ & $-22 *$ & $-24 *$ \\
\hline & Oxidisable & $3.1^{*}$ & -0.2 & -1.3 & -0.6 \\
\hline & Residual & $-7.5 *$ & -0.8 & $-5.0 *$ & $6.3 *$ \\
\hline \multirow{4}{*}{$\mathrm{Fe}$} & Exchangeable & $0.7 *$ & $0.7 *$ & 0.1 & $0.2 *$ \\
\hline & Reducible & $4.3 *$ & $2.2 *$ & $2.0^{*}$ & 1.2 \\
\hline & Oxidisable & $2.0^{*}$ & $-0.7 *$ & 1.1 & -0.2 \\
\hline & Residual & $-7.1 *$ & $-2.1 *$ & $-3.1 *$ & -1.2 \\
\hline \multirow{4}{*}{$\mathrm{Cu}$} & Exchangeable & $4.0 *$ & $3.3 *$ & -1.4 & $5.0^{*}$ \\
\hline & Reducible & -0.9 & 2.1 & -2.7 & 8.4 \\
\hline & Oxidisable & 0.8 & -3.8 & $10 *$ & -6.3 \\
\hline & Residual & -3.8 & -1.5 & -5.9 & -7.1 \\
\hline \multirow{4}{*}{$\mathrm{Pb}$} & Exchangeable & $3.0^{*}$ & $5.7 *$ & 0.0 & $5.0^{*}$ \\
\hline & Reducible & $-6.2 *$ & 2.1 & -1.4 & 0.8 \\
\hline & Oxidisable & $1.5^{*}$ & $-17 *$ & -1.8 & $-5.6^{*}$ \\
\hline & Residual & $1.6^{*}$ & $8.9^{*}$ & 3.1 & -0.3 \\
\hline \multirow{4}{*}{$\mathrm{Zn}$} & Exchangeable & -1.2 & $4.3^{*}$ & $2.2^{*}$ & 5.3 \\
\hline & Reducible & 0.7 & $-10 *$ & -1.2 & -5.1 \\
\hline & Oxidisable & $6.7 *$ & -1.1 & 0.1 & -1.2 \\
\hline & Residual & -6.3 & 6.8 & -1.1 & 1.0 \\
\hline \multicolumn{6}{|c|}{ * Significant changes $(\mathrm{t}$-test, $\mathrm{p}<0.05)$} \\
\hline
\end{tabular}

292 An overview of these transformation is shown in Figure 7, where the average calculated over the 29312 soils for each fraction of each city are compared before and after the experiment, i.e. in the 294 whole soil and on the samples at the end of the experiment after they had been dried and, consequently, re-oxidized. Differences between the fractions were tested using means before and after the submersion (Paired t-test, $\mathrm{p}=0.05$ ). Qi et al. (2014) postulated that drying of paddy soils alters the distribution of metal fractions. Urban soils, however, more frequently undergo alternating reducing-oxidizing conditions while paddy soils are submerged for long periods. It seems therefore adequate for our soils to carry out the chemical fractionation after drying. The exchangeable fraction of $\mathrm{Cu}$ increased significantly in all cities after submersion (Table 4); the residual fraction decreased in all city soils in favour of more labile forms, although the differences were not significant. In the case of $\mathrm{Pb}$ it was observed that in GLA samples the exchangeable fraction significantly increased as did the oxidisable and residual forms while the reducible fraction 
significantly decreased after submersion. In TOR and LJU there was a significant increase in the exchangeable fraction and a decrease in the oxidisable form while the SEV soils did not show any significant differences between fractions before and after submersion. These results are in line with the results of Furman and co-workers (2007), who observed an increase in Pb bioaccessibility on drying of wet soils. Silvetti et al. (2014) report an increase of $\mathrm{Pb}$ bioaccessibility after an anaerobic treatment of soils treated with industrial by-products. The trend was also observed for $\mathrm{Zn}$ that, in general, shifted from less mobile to more labile forms at the expenses of either the residue or oxidizable and reducible forms. The differences were statistically significant in GLA, LJU and SEV but not in TOR as for other metals, probably because Torino soils presented the highest variability of metal concentrations.

In addition, after wet-dry cycles $\mathrm{Fe}$ and $\mathrm{Mn}$ oxides tend to decrease their crystallinity and precipitate as amorphous phases upon oxidation (Grybos et al. 2007). This is reflected in the changes of $\mathrm{Fe}$ fractions from the residual to the reducible and exchangeable forms. This was observed in all cities and was statistically significant everywhere except in TOR where the changes were smaller. Amorphous Fe would be more susceptible to reductive dissolution than a well crystallized mineral and as a consequence the soils would be more prone to release metals on subsequent anoxia. The results of a study conducted on mine-spoil soils of Romania (Balint et al. 2014) confirm the trend towards an increased mobility of metals after oxic-anoxic cycles.

The changes in Mn extractability were much more intense in all soils, with an increase in exchangeable Mn from $18 \%$ in TOR up to the $52 \%$ in LJU soils, and a consequent decrease of the reducible fraction of the same order. This could have lead to the release of associated PTEs, explaining a fraction of the metals passed in solution after day 5 of the experiment, such as $\mathrm{Pb}$, previously found from other researchers as strongly sorbed on Mn oxides (Contin et al. 2007).

\subsection{Statistical treatment}

With the aim to better elucidate the main factors influencing metal releases we used Principal Component Analysis in addition to the already explained statistical analysis. The better explanatory results were obtained considering the concentrations of metals extracted in the first three BCR steps and the amount of metals released at specific times, namely at the beginning of the experiment, after 5 days and after 21 days of submersion. The PCA results indicate that the first four principal components explain about $69 \%$ of the data variance and Table 5 presents the factor loadings obtained using all samples.

The first factor (PC 1), representing the $28 \%$ of the total variance, present the highest loading for all $\mathrm{Fe}$ variables and for $\mathrm{Zn}$ released promptly after submersion and after 5 days. This association is probably driven by the $\mathrm{Zn}$ release from Glasgow soils, fostering the attribution to Fe dissolution and $\mathrm{pH}$ increase. The $\mathrm{PC} 2$ represented the dissolved fractions of $\mathrm{Pb}$ and $\mathrm{Cu}$ at the beginning of the 
340 experiment, associated with the exchangeable fraction of the metals, and toward the end of it, when

341 oxides already released the associated metal content.

342 The third factor is characterized by high loadings of the reducible fraction of $\mathrm{Cu}, \mathrm{Pb}$ and $\mathrm{Zn}$, 343 representing the similar behaviour of anthropic elements in urban soils, as represented also from $344 \mathrm{PC} 4$, where the oxidizable fraction of the metals is associated to the Mn release in solution at day 345 5, with $\mathrm{Pb}$.

346 Grouped, the information gathered from PCA reinforce the hypothesis of a common behaviour of 347 the heavy metal fraction emitted from anthropic activities, that in urban soil is considered to be the 348 majority.

350 Table 5 Variable loadings in the four principal components (PC) extracted using Varimax rotation.

Bold values correspond to the highest loading of each variable

\begin{tabular}{|c|c|c|c|c|}
\hline Element & PC 1 & PC 2 & PC 3 & PC 4 \\
\hline Fe 21d & 0.904 & 0.017 & -0.151 & -0.179 \\
\hline Mn 21d & 0.258 & -0.175 & 0.324 & -0.481 \\
\hline $\mathrm{Cu} 21 \mathrm{~d}$ & -0.119 & 0.896 & 0.225 & 0.091 \\
\hline $\mathrm{Pb} 21 \mathrm{~d}$ & -0.078 & 0.915 & 0.079 & 0.064 \\
\hline Zn 21d & 0.420 & 0.471 & 0.470 & 0.279 \\
\hline $\mathrm{Fe} 5 \mathrm{~d}$ & 0.807 & 0.035 & -0.270 & -0.148 \\
\hline Mn 5d & 0.343 & -0.236 & 0.126 & -0.430 \\
\hline $\mathrm{Cu} 5 \mathrm{~d}$ & -0.293 & -0.317 & -0.126 & -0.013 \\
\hline $\mathrm{Pb} 5 \mathrm{~d}$ & 0.098 & 0.210 & -0.180 & 0.627 \\
\hline Zn 5d & 0.915 & 0.069 & 0.173 & 0.103 \\
\hline $\mathrm{Cu} 0 \mathrm{~d}$ & -0.152 & 0.883 & -0.087 & 0.131 \\
\hline $\mathrm{Pb} 0 \mathrm{~d}$ & 0.108 & 0.761 & 0.261 & 0.079 \\
\hline $\mathrm{Zn} \mathrm{Od}$ & 0.892 & 0.213 & 0.242 & 0.051 \\
\hline Fe Exch & 0.886 & 0.003 & -0.112 & -0.145 \\
\hline Fe Red & 0.684 & 0.089 & 0.472 & -0.412 \\
\hline $\mathrm{Fe} O \mathrm{X}$ & 0.707 & -0.120 & 0.236 & 0.028 \\
\hline Mn Exch & -0.365 & -0.131 & 0.194 & -0.517 \\
\hline Mn Red & -0.421 & -0.383 & 0.337 & -0.308 \\
\hline $\mathrm{Mn} O \mathrm{x}$ & -0.233 & -0.225 & 0.051 & 0.654 \\
\hline $\mathrm{Pb}$ Exch & 0.252 & 0.774 & 0.121 & -0.024 \\
\hline Pb Red & 0.240 & 0.510 & 0.727 & -0.060 \\
\hline $\mathrm{Pb} \mathrm{Ox}$ & -0.162 & 0.043 & -0.059 & 0.715 \\
\hline $\mathrm{Cu}$ Exch & 0.144 & 0.653 & 0.535 & -0.124 \\
\hline $\mathrm{Cu}$ Red & 0.038 & 0.420 & 0.719 & -0.229 \\
\hline $\mathrm{CuOx}$ & -0.072 & 0.101 & 0.578 & 0.645 \\
\hline Zn Exch & 0.167 & 0.173 & 0.871 & -0.115 \\
\hline Zn Red & -0.206 & 0.065 & 0.836 & 0.051 \\
\hline $\mathrm{Zn} \mathrm{Ox}$ & 0.127 & -0.094 & 0.206 & 0.872 \\
\hline
\end{tabular}




\section{Conclusions}

355

356

357

358

359

360

361

362

363

364

365

366

367

368

369

370

371

372

373

374

375

376

377

378

379

380

381

382

383

384

The growing frequency of extreme rain events, especially in urban areas, increases the probability that soils are temporarily submerged and undergo anoxia. The selected cities offer a wide variety of climatic and urban settings and so do their soils, thus offering the opportunity of depicting a general picture of the potential threat that PTE contamination poses at the onset of anaerobiosis. The response of urban soils to submersion is more uniform than their diversity would suggest. This would confirm the hypothesis that urbanization causes homogenization of soil biota in general and soil quality in particular. Regardless of the starting $\mathrm{pH}$, organic matter, $\mathrm{Fe}$ and $\mathrm{Mn}$ oxides content in all urban soils the redox potential decreases within days from submersion. Soluble species of $\mathrm{Fe}$ and $\mathrm{Mn}$ are released, and with them $\mathrm{Cu}, \mathrm{Pb}$ and $\mathrm{Zn}$ are brought into solution. Although the absolute concentrations in solution are generally a small fraction of the total contents, and that in most cases the metals appear to be re-adsorbed by the solid matrix, the chemical fractionation before and after the experiment shows that the PTE shift towards more labile form. Also, the Fe oxides, which are the main ligand of the metals, shift towards more amorphous and easily reducible phases. The danger coming from the instantaneous release of the metals is therefore reinforced by the threat that, on subsequent submersions, these contaminants may become more and more prone to leaching to the water table and reach the aquatic compartment.

\section{Acknowledgements}

This work was conducted with the financial support of the European Commission, URBSOIL project, under contract EVK4-CT-2001-00053.

We are indebted to Luis Madrid, formerly at the Instituto de Recursos Naturales y Agrobiología of Sevilla (CSIC), Spain, for his guidance and advice. M. Biasioli is grateful to the Department of Pure and Applied Chemistry, University of Strathclyde and the Instituto de Recursos Naturales y Agrobiología of Sevilla (CSIC), Spain, where part of this research was carried out.

\section{Conflict of Interest}

The authors declare that they have no conflict of interest.

\section{References}

Ajmone-Marsan, F., Biasioli, M., Kralj, T., Grčman, H., Davidson, C. M., Hursthouse, A. S., Madrid, L., Rodrigues, S. (2008). Metals in particle-size fractions of the soils of five European cities. Environmental Pollution, 152, 73-81. https://doi.org/10.1016/j.envpol.2007.05.020 
Ajmone-Marsan, F., Biasioli, M. (2010). Trace elements in soils of urban areas. Water air and soil pollution, 213, 121-143.

Alderman, K., Turner, L. R., Tong, S. (2012). Floods and human health: A systematic review. Environment International, 47, 37-47.

Balint, R., Nechifor, G., Ajmone-Marsan, F. (2014). Leaching potential of metallic elements from contaminated soils under anoxia. Environmental Science: Processes \& Impacts 16, 211-219.

Biasioli, M., Barberis, R., Ajmone-Marsan, F. (2006). The influence of a large city on some soil properties and metals content. The Science of the Total Environment, 356, 154-164.

Biasioli, M., Grčman, H., Kralj, T., Madrid, F., Díaz-Barrientos, E., Ajmone-Marsan, F. (2007). Potentially toxic elements contamination in urban soils: a comparison of three European cities. J. Environ. Qual., 36, 70-79.

Biasioli, M., Kirby, J. K., Hettiarachi, G. M., Ajmone-Marsan, F., McLaughlin, M. J. (2010). Copper lability in soils subjected to intermittent submergence. J. Environ. Qual., 39, 20472053.

Borch, T., Kretzschmar, R., Kappler, A., Van Cappellen, P., Ginder-Vogel, M., Voegelin, A., Campbell, K. (2010). Biogeochemical redox processes and their impact on contaminant dynamics. Environ. Sci. Technol., 44, 15-23.

Buzatu, S. (2016). Cities: surviving floods and significant whims of the weather, http://www.youris.com/Environment/Methodology/Cities-Surviving-Floods-And-SignificantWhims-Of-The-Weather.k1

Ciampittiello, M., Dresti, C., Saidi, H. (2013). Analisi climatica degli eventi pluviometrici estremi. In: Le precipitazioni intense in Piemonte. Distribuzione regionale delle piogge e caratterizzazione statistica dei valori estremi. ARPA Piemonte, Torino, Italy. [in Italian]

Contin, M., Mondini, C., Leita, L., De Nobili, M. (2007). Enhanced soil toxic metal fixation in iron (hydr)oxides by redox cycles. Geoderma, 140, 164-175.

Cornell, R. M., Schwertmann, U. (2003). The iron oxides: Structure, properties, reactions, occurrences, and uses. 2nd ed. Wiley-VCH GmbH, Weinheim, Germany.

Cornu, S., Cattle, J. A., Samouëlian, A., Laveuf, C., Guilherme, L. R. G., Alberic, P. (2009). Impact of redox cycles on manganese, iron, cobalt, and lead in nodules. Soil Sci. Soc. Am. J., $73,1231-1241$.

Davranche, M., Bollinger, J. C. (2000). Heavy metals desorption from synthesized and natural iron and manganese oxyhydroxides: effect of reductive conditions. J. Colloid Interface Sci., 227, 531-539.

Donner, E., McLaughlin, M. J., Hodson, M.E., Heemsbergen, D., Warne, M. St J., Nortcliff, S., Broos, K. (2012). Ageing of zinc in highly-weathered iron-rich soils. Plant and Soil, 361, 8395. 
Du, S. Q., Shi, P. J., Van Rompaey, A., Wen. J. H. (2015). Quantifying the impact of impervious surface location on flood peak discharge in urban areas. Nat. Hazards, 76, 1457-1471. http://dx.doi.org/10.1007/s11069-014-1463-2

Du Laing, G., Rinklebe, J., Vandecasteele, B., Meers, E., Tack, F. M. G. (2009). Trace metal behaviour in estuarine and riverine floodplain soils and sediments: A review. Science of the Total Environment, 407, 3972-3985.

Florido, M. C., Madrid, F., Ajmone-Marsan, F. (2011). Variations of metal availability and bioaccessibility in water-logged soils with various metal contents: in vitro experiments. Water air and soil pollution, 217, 149-156.

Fox, M., Chari, R., Resnick, B., Burke, T. (2009). Potential for chemical mixture exposures and health risks in New Orleans post-Hurricane Katrina. Human and Ecological Risk Assessment: An International Journal, 15, 831-45.

Frohne, T., Rinklebe, J., Diaz-Bone, R. A. (2014). Contamination of floodplain soils along the Wupper river, Germany, with $\mathrm{As}, \mathrm{Co}, \mathrm{Cu}, \mathrm{Ni}, \mathrm{Sb}$, and $\mathrm{Zn}$ and the impact of pre-definite redox variations on the mobility of these elements. Soil and Sediment Contamination: An International Journal, 23, 779-799.

Furman, O., Strawn, D. G., McGeehan, S. (2007). Sample drying effects on lead bioaccessibility in reduced soil. J. Environ. Qual., 36, 899-903.

Gallant, A. J. E., Karoly, D. J., Gleason, K. L. (2014). Consistent trends in a modified climate extremes index in the United States, Europe, and Australia. Journal of Climate, X, 1379-1394.

Gasparatos, D. (2013). Sequestration of heavy metals from soil with Fe-Mn concretions and nodules. Environmental Chemistry Letters, 11, 1-9.

Groffman, P. M., Cavender-Bares, J., Bettez, N. D., Grove, J. M., Hall, S. J., Heffernan, J. B., Hobbie, S. E., Larson, K. L., Morse, J. L., Neill, C., Nelson, K., O'Neil-Dunne, J., Ogden, L., Pataki, D. E., Polsky, C., Chowdhury, R. R., Steele, M. K. (2014). Ecological homogenization of urban USA. Front Ecol Environ, 12, 74-81.

Grybos, M., Davranche, M., Gruau, G., Petitjean, P. (2007). Is trace metal release in wetland soils controlled by organic matter mobility or Fe-oxyhydroxides reduction? J. Colloid Interface Sci., 314, 490-501.

Imperato, M., Adamo, P., Naimo, D., Arienzo, M., Stanzione, D., Violante, P. (2003). Spatial distribution of heavy metals in urban soils of Naples city (Italy). Environ. Pollut., 124, 247256.

IPCC - Intergovernamental Panel on Climate Change (2013). Climate Change 2013: The Physical Science Basis. Contribution of Working Group I to the Fifth Assessment Report of the Intergovernmental Panel on Climate Change (Eds T.F. Stocker, D. Qin, G.-K. Plattner, M. Tignor, S.K. Allen, J. Boschung, A. Nauels, Y. Xia, V. Bex, P.M. Midgley), Cambridge University Press, Cambridge, UK. 
ISO - International Standards Organisation (2006). 11464 Soil quality - Pretreatment of samples for physico-chemical analysis.

ISO - International Standards Organisation (1995). 11466 Soil quality - Extraction of trace elements soluble in aqua regia.

Jha, A. K., Bloch, R., Lamond, J. (2011). Cities and flooding. A guide to integrated urban flood risk management for the 21st century. The World Bank, Washington, D.C., USA.

Jones, M. R., Blenkinsop, S., Fowler, H. J., Kilsby, C. G. (2014). Objective classification of extreme rainfall regions for the UK and updated estimates of trends in regional extreme rainfall. International Journal of Climatology, 34, 751-765.

Liu, R., Altschul, E. B., Hedin, R. S., Nakles, D. V., Dzombak, D.A. (2014). Sequestration enhancement of metals in soils by addition of iron oxides recovered from coal mine drainage sites. Soil and Sediment Contamination: An International Journal, 23, 374-388.

Madrid, F., Biasioli, M., Ajmone-Marsan, F. (2008). Availability and bioaccessibility of metals in fine particles of some urban soils. Archives of Environmental Contamination and Toxicology, $55,21-32$.

Madrid, L., Diaz-Barrientos, E., Ruiz-Cortés, E., Reinoso, R., Biasioli, M., Davidson, C. M., Duarte, A. C., Grčman, H., Hossack, I., Hursthouse, A. S., Kralj, T., Ljung, K., Otabbong, E., Rodrigues, S., Urquhart, G. J., Ajmone-Marsan, F. (2006). Variability in concentrations of potentially toxic elements in urban parks from six European cities. Journal of Environmental Monitoring, 8, 1158-1165.

McKinney, M. L. (2006). Urbanization as a major cause of biotic homogenization. Biol. Conserv., $127,247-60$.

NASEM - National Academies of Sciences, Engineering, and Medicine (2016). Attribution of extreme weather events in the context of climate change. The National Academies Press, Washington DC. http://dx.doi.org/10.17226/21852

NRC - National Research Council, Committee on Bioavailability of Contaminants in Soils and Sediments (2003). Bioavailability of contaminants in soils and sediments: processes, tools, and applications. National Academies Press, Washington D.C.

Padoan, E., Romé, C., Ajmone-Marsan, F. (2017). Bioaccessibility and size distribution of metals in road dust and roadside soils along a peri-urban transect. Scienc of the Total Environment, 601-602, 89-98.

Poggio, L., Vrščaj, B., Schulin, R., Hepperle, E., Ajmone-Marsan, F. (2009). Metals pollution and human bioaccessibility of topsoils in Grugliasco (Italy). Environmental Pollution, 157, 680689.

Popescu, I., Biasioli, M., Ajmone-Marsan, F., Stănescu, R. (2013). Lability of potentially toxic elements in soils affected by smelting activities. Chemosphere, 90, 820-826. 
Pouyat, R. V., Yesilonis, I. D., Dombos, M., Szlavecz, K., Setälä, H., Cilliers, S., Hornung, E., Kotze, D. J., Yarwood, S. (2015). A global comparison of surface soil characteristics across five cities: a test of the urban ecosystem convergence hypothesis. Soil Science, 180, 136-145.

Qi, Y., Huang, B., Darilek, J. L. (2014). Effect of drying on heavy metal fraction distribution in rice paddy soil. PLoS ONE, 9(5), e97327. https://dx.doi.org/10.1371/journal.pone.0097327

Rauret, G., López-Sánchez, J. F., Sahuquillo, A., Rubio, R., Davidson, C. M., Ure, A., Quevauviller, P. H. (1999). Improvement of the BCR three step sequential extraction procedure prior to the certification of new sediment and soil reference materials. Journal of Environmental Monitoring, 1, 57-61.

Scalenghe, R., Ajmone-Marsan, F. (2009). The anthropogenic sealing of soils in urban areas. Landscape and Urban Planning, 90, 1-10.

Schulz-Zunkel, C., Krueger, F., Rupp, H., Meissner, R., Gruber, B., Gerisch, M., Bork, H. R. (2013). Spatial and seasonal distribution of trace metals in floodplain soils. A case study with the Middle Elbe River, Germany. Geoderma, 211-212, 128-137.

Shaheen, S. M., Rinklebe, J., Rupp, H., Meissner, R. (2014). Temporal dynamics of pore water concentrations of $\mathrm{Cd}, \mathrm{Co}, \mathrm{Cu}, \mathrm{Ni}$, and $\mathrm{Zn}$ and their controlling factors in a contaminated floodplain soil assessed by undisturbed groundwater lysimeters. Environmental Pollution, 191, 223-231.

Sharma, K., Basta, N. T., Grewal, P. S. (2015). Soil heavy metal contamination in residential neighborhoods in post-industrial cities and its potential human exposure risk. Urban Ecosystems, 18, 115-132. https://doi.org/10.1007/s11252-014-0395-7

Sialelli, J., Davidson, C. M., Hursthouse, A. S., Ajmone-Marsan, F. (2011). Human bioaccessibility of $\mathrm{Cr}, \mathrm{Cu}, \mathrm{Ni}, \mathrm{Pb}$ and $\mathrm{Zn}$ in urban soils from the city of Torino, Italy. Environmental Chemistry Letters, 9, 197-202.

Silvetti, M., Castaldi, P., Holm, P. E., Deiana, S., Lombi, E. (2014). Leachability, bioaccessibility and plant availability of trace elements in contaminated soils treated with industrial byproducts and subjected to oxidative/reductive conditions. Geoderma, 214-215, 204-212.

Su, T., Shu, S., Shi, H., Wang, J., Adams, C., Witt, E. C. (2008). Distribution of toxic trace elements in soil/sediment in post-Katrina New Orleans and the Louisiana Delta. Environmental Pollution, 156, 944-950.

Van Laer, L., Degryse, F., Leynen, K., Smolders, E. (2010). Mobilization of Zn upon waterlogging riparian Spodosols is related to reductive dissolution of Fe minerals. European Journal of Soil Science, 61, 1014-1024.

Vink, J. P. M., Harmsen, J., Rijnaarts, H. (2010). Delayed immobilization of heavy metals in soils and sediments under reducing and anaerobic conditions; consequences for flooding and storage. Journal of Soils and Sediments, 10, 1633-1645. 
Violante, A., Cozzolino, V., Perelomov, L., Caporale, A. G., Pigna, M. (2010). Mobility and bioavailability of heavy metals and metalloids in soil environments. Journal of Soil Science and Plant Nutrition, 10, 268-292.

Vodyanitskii, Y. N., Plekhanova, I. O. (2014). Biogeochemistry of heavy metals in contaminated excessively moistened soils (analytical review). Eurasian Soil Science, 47. 153-161.

\section{Figure captions}

Fig. 1 Eh variation during 30 days submersion. The average value $(n=12)$ for each city is reported in black, while grey lines report the maximum and the minimum value showed from soils at each time

Fig. 2 Concentration of $\mathrm{Mn}$ in solution (percentage of the exchangeable and reducible fraction). The average value $(n=12)$ for each city is reported in black with standard deviations, while grey lines report the maximum and the minimum value showed from soils at each time

Fig. 3 Concentration of $\mathrm{Fe}$ in solution (percentage of the exchangeable and reducible fraction). The average value $(\mathrm{n}=12)$ for each city is reported in black with standard deviations, while grey lines report the maximum and the minimum value showed from soils at each time

Fig. 4 Concentration of $\mathrm{Cu}$ in solution (percentage of the exchangeable and reducible fraction). The average value $(n=12)$ for each city is reported in black with standard deviations, while grey lines report the maximum and the minimum value showed from soils at each time

Fig. 5 Concentration of $\mathrm{Pb}$ in solution (percentage of the exchangeable and reducible fraction). The average value $(n=12)$ for each city is reported in black with standard deviations, while grey lines report the maximum and the minimum value showed from soils at each time

Fig. 6 Concentration of $\mathrm{Zn}$ in solution (percentage of the exchangeable and reducible fraction). The average value $(n=12)$ for each city is reported in black with standard deviations, while grey lines report the maximum and the minimum value showed from soils at each time Fig. 7 Chemical fractions of dry soils before (on the left) and after the submersion experiment 